\title{
Fourteen cases of imposed upper airway obstruction
}

\author{
M P Samuels, W McClaughlin, R R Jacobson, C F Poets, D P Southall
}

\begin{abstract}
Imposed upper airway obstruction was diagnosed as the cause of recurrent and severe cyanotic episodes in 14 patients. Episodes started between 0.8 and 33 months of age (median 1.4) and occurred over a period of 0.8 to 20 months (median 3.5). Diagnosis was made by covert video surveillance, instituted after either (a) the observation that episodes began only in the presence of one person, or (b) characteristic findings on physiological recordings, lasting between 12 hours and three weeks, performed in hospital or at home.

Surveillance was undertaken for between 15 minutes and 12 days (median 24 hours) and resulted in safety for the patient and psychiatric assessment of the parent: mother $(n=12)$, father $(n=1)$, and grandmother $(n=1)$. These revealed histories of sexual, physical, or emotional abuse $(n=11)$, self harm $(n=9)$, factitious illness $(n=7)$, eating disorder $(n=10)$, and previous involvement with a psychiatrist $(n=7)$. Management of the abusing parents is complex, but recognition of their psychosocial characteristics may allow earlier diagnosis.

Imposed upper airway obstruction should be considered and excluded by physiological recordings in any infant or young child with recurrent cyanotic episodes. If physiological recordings fail to substantiate a natural cause for episodes, covert video surveillance may be essential to protect the child from further injury or death.
\end{abstract}

Suffocation by parents of their offspring is recognised as a dangerous form of child abuse. ${ }^{1-4}$ It may present as recurrent cyanotic episodes,

Table 1 Clinical details of infants subject to imposed upper airway obstruction

\begin{tabular}{|c|c|c|c|c|c|c|}
\hline $\begin{array}{l}\text { Case } \\
\text { No }\end{array}$ & $\begin{array}{l}\text { Sex } \\
\text { of } \\
\text { infant }\end{array}$ & $\begin{array}{l}\text { Age at onset } \\
\text { of cyanotic } \\
\text { episodes } \\
\text { (months) }\end{array}$ & $\begin{array}{l}\text { No of times } \\
\text { admitted } \\
\text { to hospital }\end{array}$ & $\begin{array}{l}\text { No of episodes } \\
\text { requiring } \\
\text { resuscitation }\end{array}$ & $\begin{array}{l}\text { No of } \\
\text { siblings }\end{array}$ & $\begin{array}{l}\text { Previous } \\
\text { sudden infant } \\
\text { death }\end{array}$ \\
\hline $\begin{array}{r}1 \\
2 \\
3 \\
4 \\
5 \\
6 \\
7 \\
8 \\
9 \\
10 \\
11 \\
12 \\
13 \\
14\end{array}$ & $\begin{array}{l}M \\
\mathrm{~F} \\
\mathrm{~F} \\
\mathrm{~F} \\
\mathrm{M} \\
\mathrm{M} \\
\mathrm{F} \\
\mathrm{F} \\
\mathrm{M} \\
\mathrm{M} \\
\mathrm{F} \\
\mathrm{M} \\
\mathrm{M} \\
\mathrm{F}\end{array}$ & $\begin{array}{r}0.8 \\
0.8 \\
2.5 \\
3.8 \\
10.0 \\
1.3 \\
4.0 \\
33.0 \\
1.5 \\
0.8 \\
4.0 \\
1.0 \\
1.0 \\
0.8\end{array}$ & $\begin{array}{r}6 \\
5 \\
6 \\
6 \\
19 \\
5 \\
3 \\
6 \\
4 \\
4 \\
3 \\
5 \\
6 \\
3\end{array}$ & $\begin{array}{r}>20 \\
7 \\
5 \\
8 \\
7 \\
4 \\
7 \\
8 \\
4 \\
2 \\
>20 \\
2 \\
4 \\
3\end{array}$ & $\begin{array}{l}2 \\
1 \\
0 \\
2 \\
2 \\
1 \\
0 \\
1 \\
0 \\
4 \\
3 \\
0 \\
2 \\
1\end{array}$ & $\begin{array}{l}\text { No } \\
\text { No } \\
\text { No } \\
\text { Yes } \\
\text { No } \\
\text { No } \\
\text { No } \\
\text { No } \\
\text { No } \\
\text { Yes } \\
\text { No } \\
\text { No } \\
\text { No } \\
\text { Yes }\end{array}$ \\
\hline
\end{tabular}

Needing mouth to mouth resuscitation or vigorous stimulation.

recurrent life threatening events, or progress to sudden and unexpected death. A parent, usually the mother, but sometimes the father, ${ }^{5}$ may abuse one or more of her/his children for prolonged periods of time before the diagnosis is made. ${ }^{6}$

A diagnosis of imposed upper airway obstruction is difficult to substantiate. Covert video surveillance (CVS) has been used in this situation, ${ }^{78}$ being of particular value in obtaining sufficient legal evidence to guarantee the safety of the child. ${ }^{9}$ Our use of this technique in patients presenting with recurrent cyanotic episodes has produced information on the psychopathology of the abusing parent. This may help physicians to consider the possibility of suffocation by a parent early in the clinical course of this problem.

\section{Patients and methods}

Between March 1986 and February 1991, 14 patients were diagnosed as having imposed upper airway obstruction. They had been referred to our department for the investigation of their recurrent cyanotic episodes at between 1.5 and 33 months (median 5.5 months) of age (table 1). The patients had been admitted to their local general and/or teaching hospitals between three and 19 (median five) occasions. Numerous investigations had been performed on these patients before referral, including barium studies, oesophageal pH monitoring, lumbar punctures, computed tomograms, and numerous venepunctures. Twelve sets of parents had been issued by their paediatrician with a breathing movement monitor (Graseby) for use at home to detect further 'apnoeic' events.

The accuracy of the details of the cyanotic episodes is dependent in part on the histories obtained from the perpetrators of the abuse. Cyanotic episodes were reported to have commenced at a median age of 6 weeks (range 0.8-33 months). Each patient was described as having suffered between two and 30 episodes, including a total of 34 requiring mouth to mouth resuscitation with/without external cardiac massage. In each patient, between one and 10 cyanotic episodes (median three, total 55) requiring vigorous stimulation, additional inspired oxygen or cardiopulmonary resuscitation, were definitely witnessed to have occurred (but not observed to begin) by nursing and/or medical staff in either the referring or our own hospital.

These patients had a total of 13 siblings and six half siblings, including three who had 
previously died suddenly and unexpectedly. The suspected perpetrators of the abuse included 12 mothers, one father, and one grandmother. Eleven of the infants had married parents, one of whom was separated. For the remaining three patients, one had a parent living with a common law spouse and two had single parents. The grandmother who was suspected of performing the abuse was the mother of one of these single parents and was herself living with a common law spouse.

Imposed upper airway obstruction was considered to be the likely diagnosis at the referral of eight of the 14 patients. One of these eight patients had petechial haemorrhages on the face and neck after a cyanotic episode. Their paediatricians did not consider, however, that they had sufficient evidence to confront the parent confidently and be sure of securing the long term safety of the child. The remaining six patients were referred for the management of recurrent cyanotic episodes considered to be due to a natural pathophysiology.

\section{PROTOCOL FOR INSTITUTING CVS}

When the circumstantial evidence was sufficient to suggest imposed upper airway obstruction, an informal multidisciplinary case meeting was held in order to decide whether to institute CVS. ${ }^{8}$ This meeting involved medical, nursing, social services, and administrative staff from the Royal Brompton Hospital, local police officers (usually including the detective chief inspector), and members of the medical, nursing, and social services staff from the referring hospital. Approval for the use of CVS was given by the ethics committee of the Royal Brompton Hospital and an external working party.

The evidence upon which it was considered appropriate to proceed with CVS included, firstly, that all episodes had started in the presence of the same person (as far as could be clarified) and, secondly, that there was a characteristic pattern on the physiological recordings during a cyanotic episode.

Although it was usually apparent that episodes only began in the presence of the abusing parent, it was not uncommon for members of staff to report that they had witnessed cyanotic episodes. It later transpired that the onset of the episode invariably occurred only when the parent was left alone or unobserved with the child. In one case, where the grandmother was inducing the episodes, the mother had reported that she had seen an episode begin. This was later considered to be her lack of appreciation as to what constituted the beginning of an episode.

Long term multichannel physiological recordings, lasting for between 12 hours and three weeks, were used to exclude or suggest imposed airway obstruction. ${ }^{10}$ These involved recordings of arterial oxygen saturation $\left(\mathrm{SaO}_{2}\right)$ from a pulse oximeter (Nellcor $\mathrm{N}-200$ ) modified to give beat to beat measurements, the photoplethysmographic waveforms from the pulse oximeter to verify $\mathrm{SaO}_{2}$ measurements, breathing movements from an abdominal volumatic capsule (Graseby), electrocardiogram, heart rate, and airflow from a nasal thermistor. In some cases, two channel electroencephalogram (centrotemporal in origin) was recorded.

A pattern considered suggestive, but not diagnostic, of imposed upper airway obstruction has been previously reported. ${ }^{78}$ Usually the recording showed regular breathing which was suddenly interrupted by the onset of large movement artefact on the breathing movement signal in combination with a pattern of obstruction-that is, continued breathing movements, absent airflow, and a gradual fall in $\mathrm{SaO}_{2}$. In addition, there was an initial sinus tachycardia, followed by a bradycardia when severe hypoxaemia supervened.

In two of the 14 patients, cyanotic episodes failed to occur during their first admission to the Royal Brompton Hospital. As their episodes were initially considered by us to be due to natural causes, these patients were discharged with home monitoring equipment which detects sudden, potentially life threatening falls in transcutaneous oxygen tension. ${ }^{11}$ In one of these patients (case 13), the monitor incorporated an event recorder that stored transcutaneous oxygen tension, breathing movements, and electrocardiogram in the event of an alarm. Both patients were readmitted because of further life threatening events; in the child on the event recorder, data was recorded during a major life threatening event at home requiring mouth to mouth resuscitation by the father and ambulance staff (figure).

After a decision by the planning meeting to institute CVS, this was started in our own unit in 10 cases and at the referring hospital in four cases. In our own hospital, the surveillance equipment was established by the Metropolitan Police Technical Services Department, contacted via the detective chief inspector who had attended the planning meeting. When CVS was undertaken in the referring hospital, medical staff from the Royal Brompton Hospital and police officers already experienced in this technique helped to institute and manage the surveillance.

Surveillance was undertaken by installing one or two cameras (details unavailable due to police confidentiality), obscured from normal view, in the ceiling and wall of the cubicle in which the patient was nursed. When one camera was used, this was placed within a false ceiling directly over the infant's cot at a height of about $2 \cdot 8$ metres above the floor level. To prevent the camera overhead being obscured by the parent leaning too far over the cot, a wall camera was also installed at a height of $1 \cdot 8-2 \cdot 0$ metres above the floor, directly opposite and $1 \cdot 5-2 \cdot 0$ metres from the end of the cot. To continue surveillance at night, a low level light remained on above the cot.

Both cameras were connected to a video monitor (Hitachi VM-920K) and video cassette recorder (Sony Betamax VCR SL-HF 950) in an office close to the patient's cubicle. Two women police officers (to allow for one to leave the office for essential activities), working eight hour shifts, continuously observed and recorded the patient's activities. The six police officers required in any 24 hour period were usually supplied from the police station local to where 


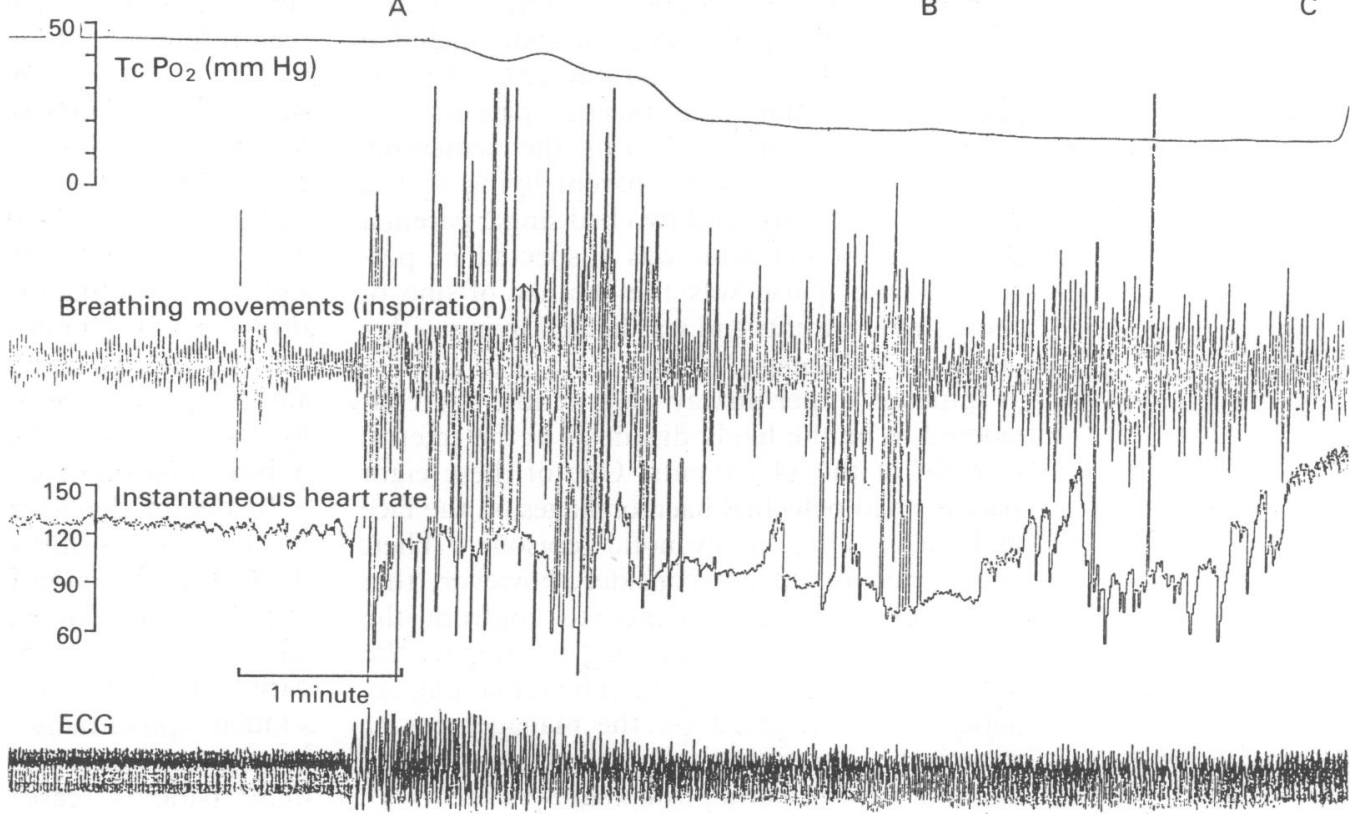

the surveillance was being performed. In addition, a registered mental nurse sat in on the surveillance in seven cases, in order to deal with any distressing response manifest by the parent. The patient was maintained within view of the camera(s) by being continuously attached to the physiological recording equipment, which was established in such a way that the infant was retained at all times on the cot.

A relatively senior member of the nursing staff was selected from each nursing shift to remain within close proximity of the patient's cubicle. When police officers had observed the parent suffocating the patient for between 10 and 15 seconds, they alerted this nurse, either by direct contact or by a portable intercom, depending on the proximity of the office to the cubicle. The nurse then entered the cubicle and, as a priority, ensured that the patient's medical condition was satisfactory. This resulted in a delay of approximately 15-25 seconds from the onset of the airway obstruction before the episodes were interrupted. From past recordings of physiological data during unobserved events it had been established that hypoxaemia sufficiently severe as to cause electroencephalograph changes indicative of cerebral hypoxia occurred 50-70 seconds after the onset of obstruction. ${ }^{78}$ This delay was therefore considered sufficient to allow the video evidence to be adequate for legal purposes, but without the risk of cerebral hypoxia.

\section{PSYCHIATRIC OBSERVATIONS}

At the beginning of surveillance, contact was made with a psychiatrist from the patient's locality, so that immediate assessment and follow up of the perpetrator could be achieved after diagnosis of the abuse. These 14 different psychiatrists were later contacted, their records were examined and consensus achieved on the main diagnostic categories. To verify reports given to the psychiatrists by the parents, additional information was obtained from the general practice records of the perpetrator and the social service departments local to the referring hospitals.

\section{Results}

During CVS, the nursing staff and police officers commented on how little the parent handled, played, and talked to the child when alone in the cubicle. Just before the attempt at suffocation, the parent often became still and watchful, usually for several minutes, before organising the patient's position in the cot, and, in two cases securing a blanket over the chest and arms in an attempt to restrain the child.

CVS was required for between 15 minutes and 12 days (median 24 hours) before suffocation was identified (table 2 ). The patient usually lay face up in the cot while the parent, having ensured that no interruption was likely to occur, occluded the airway by firmly covering the mouth and nose with one or both hands $(n=9)$, an article of the patient's clothing $(n=2)$, a piece of cotton fabric $(n=1)$, or a length of domestic plastic film $(n=1)$. In the remaining patient, fingers were inserted into the back of the mouth. In all cases, the patient struggled violently, but either the continual pressure on the infant's face or the holding of the infant's arms limited the ability of the patient to overcome the assault. No patient showed facial 
Table 2 Details of abuse, CVS, and outcome for infants and siblings

\begin{tabular}{|c|c|c|c|c|c|c|}
\hline $\begin{array}{l}\text { Case } \\
\text { No }\end{array}$ & $\begin{array}{l}\text { Age at } \\
\text { discovery } \\
\text { of abuse } \\
\text { (months) }\end{array}$ & $\begin{array}{l}\text { Duration } \\
\text { of abuse } \\
\text { (months) }\end{array}$ & $\begin{array}{l}\text { CVS in } \\
\text { referring } \\
\text { hospital } \\
\text { or } R B H^{*}\end{array}$ & $\begin{array}{l}\text { Duration } \\
\text { of } \\
\text { CVS }\end{array}$ & $\begin{array}{l}\text { Outcome } \\
\text { for } \\
\text { infant }\end{array}$ & $\begin{array}{l}\text { Outcome } \\
\text { for } \\
\text { siblings }\end{array}$ \\
\hline $\begin{array}{r}1 \\
2 \\
3 \\
4 \\
5 \\
6 \\
7 \\
8 \\
9 \\
10 \\
11 \\
12 \\
13 \\
14\end{array}$ & $\begin{array}{c}21 \\
6 \\
5 \\
7 \cdot 5 \\
17 \\
3 \\
5 \cdot 5 \\
34 \\
6 \cdot 5 \\
1 \cdot 5 \\
10 \\
7 \cdot 5 \\
3 \\
4\end{array}$ & $\begin{array}{l}20 \\
5 \\
2 \cdot 5 \\
3 \cdot 7 \\
7 \\
1 \cdot 8 \\
1 \cdot 5 \\
1 \\
5 \\
0 \cdot 8 \\
6 \\
6 \cdot 5 \\
2 \\
3 \cdot 2\end{array}$ & $\begin{array}{l}\text { RBH } \\
\text { RBH } \\
\text { RBH } \\
\text { RBH } \\
\text { RBH } \\
\text { RBH } \\
\text { RBH } \\
\text { Referring hospital } \\
\text { RBH } \\
\text { Referring hospital } \\
\text { Referring hospital } \\
\text { Referring hospital } \\
\text { RBH } \\
\text { RBH }\end{array}$ & $\begin{array}{l}18 \text { hours } \\
4 \text { hours } \\
48 \text { hours } \\
12 \text { days } \\
24 \text { hours } \\
48 \text { hours } \\
1 \cdot 5 \text { hours } \\
36 \text { hours } \\
45 \text { mins } \\
9 \text { days } \\
15 \text { mins } \\
24 \text { hours } \\
3 \text { hours } \\
29 \text { hours }\end{array}$ & $\begin{array}{l}\text { Adopted } \\
\text { With parents } \\
\text { Adopted } \\
\text { With parents } \\
\text { Adopted } \\
\text { Adopted } \\
\text { Adopted } \\
\text { Adopted } \\
\text { Fostered } \\
\text { With mother } \\
\text { Fostered } \\
\text { Adopted } \\
\text { With father } \\
\text { With parents }\end{array}$ & $\begin{array}{l}\text { With father } \\
\text { With parents } \\
\text { Nil } \\
\text { With parents } \\
\text { With parents } \\
\text { With parents } \\
\text { Nil } \\
\text { Adopted } \\
\text { Nil } \\
\text { With mother } \\
\text { Fostered } \\
\text { Nil } \\
\text { With father } \\
\text { Deceased }\end{array}$ \\
\hline
\end{tabular}

${ }^{*}$ RBH, Royal Brompton Hospital.

tSee table 1 . however, the seriousness of their behaviour, any intent of harm, and any part in inducing previous episodes. A few parents stated that they had performed the abuse in order to make it clear to the medical staff that their child did have a major medical problem. Alternatively, parents stated that they had merely been playing with or handling the child; one of these persisted with the idea that the child was being played with even after the court case had found her guilty.

After an appearance before a magistrate, bail was given in 12 cases. Although not a condition of the bail, the magistrates recommended that the parent undergo psychiatric assessment. Two parents were remanded in custody: one was given bail after a week (case 7), while the other (the only father) was held on a charge of attempted murder of this infant (case 10) and actual murder of a previous one. Excluding the grandmother in case 14, who is awaiting trial, 11 out of 13 parents subsequently pleaded guilty in court. All 13 were found guilty; 12 were given probational sentences and one (case 10) was given a life sentence.

All patients were subsequently transferred via the local hospital into the care of the local social services department. Case conferences were held to establish a child protection plan. There were clearly serious risks in leaving the patient in the care of the abusing parent. ${ }^{3} 12$ It was considered that this risk might be acceptable in the future if there was evidence of a change in the parent's attitude-as documented, for example, after psychotherapy. ${ }^{13}$ In some cases the parents of the abusing parent requested care and control of the patient. This was rejected as it was considered likely that some responsibility for the abuse may have resulted from their poor parenting during the abuser's childhood. It was also considered that the siblings of the patient were at risk of abuse and appropriate supervision and care was provided for them through the social services authority. 37

Patient outcome is summarised in table 2 . Cyanotic episodes did not recur in any patient after diagnosis of the abuse, further confirming their unnatural mechanism. At present cases 9 and 11 are fostered, pending the final decision of High Court proceedings. Six out of 19 siblings remain in the care of the abusing parent:

After disclosure of the abuse, three parents underwent inpatient psychiatric assessment (two of whom continued as outpatients) and seven received regular follow up. In four cases, only a single assessment by a psychiatrist was undertaken. Psychosocial data on the abusing parents are summarised in table 3.

PARENTAL HISTORY

A history of abuse in their childhood was obtained from 11 parents. This was confirmed by previous social service records in seven. A history of childhood sexual abuse was disclosed by seven parents and may have occurred in a further two cases. The perpetrator of this sexual abuse had been the stepfather in three cases (in one of these, older stepbrothers had also been 
involved), grandfather in two cases, father in one case, and uncle in one case.

Physical abuse was disclosed in seven cases: five by a male parent, four of whom were involved in the sexual abuse, and two by the mother. In one additional parent, there was a history of severe emotional abuse (possibly also with sexual abuse). For all cases, there was a history of impaired or inadequate parenting as a child: their own parents were frequently described as strict and overprotective, allowing little emotional expression. The parents of cases 4,7 , and 11 were in local authority care during their childhood, including a combination of children's homes and foster care; this was at the age of 8-16, 13-17, and 12-16 years respectively.

Nine of the perpetrators had well documented histories suggestive of a conduct disorder. These included faecal smearing (case 12), petty crime (cases 2, 4, 5, 7, 10, and 13), running away from home (case 9), teenage prostitution (case 13), and suspected arson (case 13). Nine parents had definite histories of self harm: six had taken overdoses of medication, one had swallowed bits of razor blades and carpentry nails (case 10), and one had mutilated her arms and wrists (case 4). On diagnosis of the abuse, one parent pulled out her toenails (case 5). Seven parents had a history of factitious symptoms: this most commonly involved undiagnosed 'fainting fits' during teenage years.

Ten of 14 parents had eating and/or weight problems: five had previously seen medical practitioners for anorexia and weight loss (three of whom had also been diagnosed as anorexic), and five had been grossly overweight.

Seven parents had at some time in their past consulted a psychiatrist: two for anorexia, two for depression, and three for child psychiatric problems relating to their conduct disorders.

Cases 1 and 2 have been previously described in detail. ${ }^{8}$ For the remaining 12 abusing parents clinical features, additional to those in table 3, are described below. The details are known to be authentic, except in the case where it is stated that the parent (perpetrator) reported, alleged, or disclosed the information.

Case 3

This mother was the middle of three children. Her own mother was an anxious woman who would take to her bed for days at a time, and her father was a rigid man with high expectations. She denied any abuse as a child, although she reported emotional maltreatment. She suffered from numerous vague complaints (for example, abdominal pain), which resulted in frequent absence from school. Despite a history of teenage depression, overdoses of paracetamol, hyperventilation, fainting episodes, and anorexia nervosa she progressed well at school and obtained three ' $A$ ' levels. Contraceptive failure led to pregnancy and forced a marriage. Her child is now adopted, and she and her husband continue to live in her parents' home.

Case 4

This mother was one of three children, all by different fathers. She had a long history of conduct disorder and was in local authority care between 8 and 16 years of age. She developed severe variability in her weight and had been seen by a psychiatrist for an eating disorder. She had also mutilated her arms and wrists. At 17 years of age she married a man 30 years her senior. Her previous child had died two years before the present case, suddenly, unexpectedly, and without explanation at the age of 3.5 months. After the abuse was diagnosed, she disclosed a history of childhood sexual abuse by her stepfather. The abused child and an unaffected older brother were cared for by foster parents until the latter was returned six months later and the affected child four months after that. The mother was described as having 'matured considerably'.

\section{Case 5}

This mother was described as having strict Salvationist parents. Her father was in the armed forces. She did not report childhood abuse. Between 13 and 19 years of age, she had 'fits' which were thought to have a 'strong hysterical component'. At 15 years, she was seen by a child psychiatrist for lying and stealing, interpreted as a rejection of her parents' strict Salvationist principles.

\section{Case 6}

This mother, an only child, reported a poor relationship with her parents. At 6 years of age she had been sexually abused by an uncle. Between 12 and 16 years she was diagnosed as having 'psychogenic fainting fits'. She underwent two brief psychiatric admissions: at 17 after an overdose and at 23 when she presented 'depressed'. She had a wide variation in her body weight and was grossly overweight at the time the abuse was diagnosed. After diagnosis, she is considered to 'have progressed well' with restoration of normal body weight.

\section{Case 7}

This mother was rejected by her own mother at an early age. She was in local authority care between 13 and 17 years because of being 'out of control'. She reported sexual abuse by her stepfather, had a long history of being severely overweight, and had numerous admissions after overdoses, feigned asthma, and spurious claims of labour throughout pregnancy. She was a single mother, whose baby was made a ward of court shortly after birth because of concerns about her parenting ability. The mother was given unsupervised access one night a week to the infant when she was 4 months old, whereupon the cyanotic episodes began. After diagnosis of the abuse she was remanded in custody for one week. The registered mental nurse observing the video screen reported 'that the infant appeared a happy and active child. When her mother approached her, however, she became quieter and for long periods stared in the direction of the mother. After the abuse, the 
infant was very distressed initially, but subsequently quiet and unmoving'.

\section{Case 8}

This mother was the youngest of five children: her mother was reported as being strict and overprotective. She reported frequent beatings as a child, was unable to be left alone or to mix with other children. No history of sexual abuse was disclosed. At 21 years of age she married a man dependent on alcohol, but she continued to live in her mother's home. During the pregnancy, she planned to have her child adopted, but subsequently changed her mind. Before the cyanotic episodes began, the baby was admitted on several occasions with failure to thrive: no organic cause had been found.

\section{Case 9}

This mother was an only child, whose parents separated when she was a teenager after a stormy, violent marriage. Her own mother was described as a vulnerable and emotional woman and extremely demanding. No history of childhood abuse was disclosed. At 16 years of age she ran away from home, married a young, violent, man dependent on alcohol and had an unplanned pregnancy. After confrontation and a court case, both the mother and the maternal grandmother have persistently denied that the child had been harmed (they have not seen the video recording of the abuse).

\section{Case 10}

The perpetrator of the abuse in this case was the father. A child by his cohabitee's previous relationship had died suddenly two years earlier after recurrent, unexplained cyanotic episodes which had always occurred in his presence. He had a history of feigning abdominal pain and seizures as well as ingesting metal such as nails and pieces of razor blades. He had a previous psychiatric hospital admission, claiming to be depressed, but discharged himself after two days. He had also falsely claimed to have leukaemia. He had a poor work record and had used false references to obtain employment.

During the CVS and before imposing upper airway obstruction, he was observed to abuse the infant verbally and physically. This included painfully pinching and waking the baby and sticking his fingers down the child's throat. He eventually pleaded guilty and was sentenced to life imprisonment for attempted murder of this infant and for the murder of the previous infant.

\section{Case 11}

This mother was born to an English mother and a Pakistani father who separated when she was a baby. There was a series of stepfathers, one of whom along with his sons sexually and physically abused her. She was rejected by her mother from an early age and spent several years in the care of the local authority. She had a problem with school truancy, took overdoses of medi- cation on several occasions, and was seen by her family physician for anorexia. At 17 years, she married a Muslim man, became pregnant, failed in her attempt to induce an abortion, and the resulting child became the abused child. An older sibling appeared to be unaffected. Before starting the CVS, the child was nursed in a cubicle near to the nurses' station for 12 days with no cyanotic episodes. The mother was then left alone with the child and CVS started: 15 minutes later she was seen to smother the infant.

\section{Case 12}

This mother is one of three children whose family were 'well known to the social services'. Her parents separated when she was 5 years old and she was described as having limited parenting with physical abuse by her mother. She had attended a school for behaviourally disturbed children, where she smeared the wall with faeces. She also had a history of cruelty to pets. At 16 years she alleged rape but no police prosecution followed, and at 17 years she and her sister were put on probation for abducting a baby from a local hospital. Around this time she took an overdose of medication and also attended her general practitioner for anorexia. During the pregnancy she had numerous 'collapses' which were thought to be psychogenic in origin.

\section{Case 13}

This mother had three children, the eldest of whom had previously failed to thrive. As a teenager, she had alleged rape on two occasions, but these allegations had turned out to be false. She had also alleged blackouts and a seizure, which could not be medically substantiated. She was suspected of setting fire to her own home and of making anonymous phone calls to the social services about her own children being at risk of abuse. After diagnosis she continued to deny any responsibility for the abuse. She was seen on one occasion by a psychiatrist and refused any further follow up. She has since separated from her husband, who now cares for their children.

\section{Case 14}

This case involved the maternal grandmother. She had suffered an unhappy childhood including sexual and physical abuse by her father, who drank heavily. Her own daughter was a single parent when the first grandchild was born (the patient's brother) and most of his care was given by the grandmother. This child had recurrent, life threatening cyanotic episodes from the age of 3 weeks until his sudden death during a typical cyanotic episode at the age of 11 months. All of these episodes began in the presence of his grandmother. On numerous admissions to hospital this infant had subtherapeutic levels of anticonvulsants. The grandmother offered to take over care for the subsequent child soon after she presented with similar cyanotic episodes, because the mother 
was frightened about caring for her new daughter, considering that she might also die during one of her cyanotic episodes. The grandmother had moved house on many occasions and it was difficult to obtain accurate records of her medical history.

The psychiatric diagnosis made in all cases was that of a personality disorder. Parents' attitudes and behaviour have appeared to improve in two cases, in one thought to be due to the psychotherapy given by the psychiatrist (case 2). Since the abuse five sets of parents have separated from their spouses.

During the five year study period, there was one further case in which CVS was performed. This case was a subsequent sibling from a family in which there had been three sudden unexplained infant deaths. After reports of two cyanotic episodes at 6 weeks and 3.5 months of age, the child underwent CVS lasting for eight days when 5 months old. No episodes occurred during surveillance, but this child was later made a ward of court after a confession by the mother that she had caused the other three deaths-a confession that was subsequently retracted.

\section{Discussion}

Imposed upper airway obstruction or suffocation is a dangerous form of child abuse with a high risk of sudden death. Meadow recently reported 27 index cases of parental suffocation and 33 siblings; in all there was an overall mortality of $45 \%$. $^{3}$ Cyanotic/apnoeic episodes or seizures had occurred in $82 \%$ of the cases and dead siblings. $^{3}$ In addition to the risk of sudden death, such patients are at risk of hypoxic cerebral injury and may suffer significant psychological morbidity; subsequent behaviour disturbance is common. ${ }^{12}$ The risks of similar abuse to siblings is high. ${ }^{6} 12$

When infants or young children present with recurrent cyanotic episodes, the physician usually assumes the parent to be truthful. Under certain circumstances, however, the physician must decide whether the story the parent gives is one of overexaggeration, entirely factitious symptoms, or real symptoms occurring as a result of abuse. ${ }^{14}$ Physiological recordings may help to differentiate between these different situations, particularly if data can be recorded during the episodes. ${ }^{78}$ This form of documentation may be invaluable not only as evidence to confirm abuse, but also to distinguish between a factitious history (no pathophysiology), a history of real symptoms (natural pathophysiology), and a history of real, but imposed symptoms (unnatural pathophysiology). If cyanosis or hypoxaemia has been observed by someone other than the parent who has given the history, or has been documented by physiological recordings or acid-base disturbance, and could possibly be the result of the parent suffocating the child, then the physician must consider action to ensure the child's safety.

Direct confrontation with the parents may result not only in denial by the parent (as found in all 14 of our cases before the CVS evidence was revealed), but also in loss of medical follow up for the infant and thereby an inability to secure safety for the child-that is, removal of the child from the abusing parent. ${ }^{15}$ Leaving the child with the parent, even under close supervision by social workers, may be dangerous, particularly as continuation of abuse may occur in hospital and after discovery, indicating 'poor parental control of the impulse to harm the child'. ${ }^{12}$ Confirmation of the diagnosis has to date usually been reliant upon circumstantial evidence, but this may be insufficient in court to ensure protection of the child. ${ }^{9}$ The court may wish, for very good reasons and in the absence of definitive evidence, to continue child rearing within the biological family. All 14 parents in this report were extremely plausible and in many cases possessed considerable charm. Without unequivocal evidence, they could have argued their case effectively in court.

To secure unequivocal evidence and thus obtain legal separation of the child from his/her abuser, video tape evidence during a typical cyanotic episode was collected. ${ }^{78}$ The performance of video surveillance without parental knowledge is clearly an infringement of trust between the paediatrician and the parents. ${ }^{9}$ Before commencing CVS, therefore, there should be a strong suspicion of abuse, although the information upon which this is based will usually be insufficient to guarantee that a court will separate the child from its parents. Above all, CVS is performed because the prime concern of the paediatrician is for the rights of the child. In retrospect, a positive result from CVS can then, in our opinion, be considered justified. To date, no child has undergone CVS and found to have a natural (non-abuse) cause for their cyanotic episodes.

Meadow has suggested that CVS may have a low sensitivity for detecting parental suffocation as the infant may not suffer a cyanotic episode while in hospital and under surveillance. ${ }^{3}$ In all but one of the 15 patients undergoing CVS after referral to our unit with recurrent cyanotic episodes considered to be due to suffocation, parents have attempted to induce episodes while in hospital and within close proximity of staff. It also became clear that parents were more likely to impose airway obstruction when, due to close nursing observation, they had been unable to demonstrate their child's 'symptoms' for a period of time. The median duration of surveillance required before diagnosis was 24 hours-fortunately short in view of the staffing and equipment required to perform CVS.

Despite unequivocal video evidence of suffocation, some magistrates and judges expressed incredulity that a parent could have performed such behaviour on their child. Once again this fact highlights the need to obtain, whenever this can be achieved, unequivocal data in all cases of child abuse, particularly when this involves recurrent suffocation.

The underlying reasons why parents abuse their children in this way remain unclear. A behaviour pattern in which symptoms or signs are fabricated in children has been given a variety of labels, including most commonly, Munchausen syndrome by proxy. However, 
unlike adults with Munchausen's syndrome, these parents have not invented a variety of progressively more bizarre symptoms and did not appear to seek out intentionally a number of different specialists. In our cases, the parent had usually identified only one paediatrician to look after the child's problem before referral.

Psychiatric evaluation of offending parents has not been well documented. In the case of childhood poisoning, Rogers et al hypothesised that the parents may have been creating a situation which enables them to escape from there own physical or psychological illnesses, marital or social problems. ${ }^{16}$ This does not appear to explain, however, the form of abuse seen in these present patients. Thus none of the parents appeared to have encountered a new stress in their life situation. In addition, these parents did not appear to smother the child in anger or in an attempt to silence them: their actions appeared well thought out and were performed calmly and carefully.

Meadow has previously reported that $18 / 47$ of abusing parents had themselves reported factitious illness or symptoms, ${ }^{17}$ and Alexander et al reported this in four of five mothers. ${ }^{6}$ Nine of our 14 cases had a history of previous factitious illness or self harm. This behaviour may stem from a low self esteem, resulting from early childhood experience such as poor parenting or frank abuse, as so explicitly reported in 11 out of 14 of these cases. Meadow reported a history of sexual or physical abuse in childhood of at least $25 \%$ of the parents performing these acts. ${ }^{3}$ $\mathrm{He}$ also reported possible emotional abuse in $70 \%$ of cases.

Poor parenting may make it difficult for a child to develop normal emotional expression and, in adulthood, this may result in difficulties in differentiating her/his own emotions from those of the infant. If the mother tends to harm herself, then the child may also be at risk of harm. Clearly the drive to be harmed or cause harm must be strong; it may be a form of self inflicted punishment for having been such a 'problem' for their own parents or not conforming to their parents' expectations. The attachment to, and conflicting emotions for, the abused infant may be less likely to play as important a part in the two cases in which the father and grandmother were the perpetrators. These cases both involved previous sudden infant deaths and appear to be even more complex.

In an assessment of mothers who had fatally abused their children, Korbin found a history of childhood maltreatment, predominantly physical, to be the most consistently reported characteristic in the parents. ${ }^{18}$ Tuteur and Glotzer also found severe childhood emotional deprivation in a study of mothers committing infanticide. ${ }^{19}$ It remains unclear how commonly a history of childhood maltreatment results in this intergenerational cycle of abuse. There may be many parents who, having been abused in their own childhood, never abuse their own children. Prospective work on child rearing practices may help to determine how often abuse in early childhood results in this form of abuse.
Eating disorders have not previously been reported in parents who suffocate their children. Lacey and Evans have reported that bulimia is associated with multi-impulse behaviour. ${ }^{20}$ Many of the abusing parents demonstrated this behaviour in, for example, overdosing, self mutilation, stealing, fire setting, and petty crime. The significance of eating disorders in parents who suffocate their babies is unknown, but it might be considered as a form of self harm. Similarly, the proportion of impulsive women who harm their babies in this way is unknown.

All our abusing parents received a primary diagnosis of 'personality disorder'. This is a vague and unsatisfactory label as it adds little to our understanding of the psychopathology of these parents. Furthermore treatable mental disorders (for example, depression and anorexia) were often omitted from the final diagnosis, when they appeared to be frequently described in the psychiatric histories. Possible reasons for this discrepancy include the difficulty in differentiating genuine from factitious symptoms in some cases. A severe personality disturbance may predominate over the presentation or detection of other mental disorders. These factors may contribute to the frequency, yet variable and inconsistent nature of psychiatric input in the cases of our perpetrators.

Before a diagnosis of the abuse, seven out of 13 parents had been attended by psychiatrists, a similar finding to the four out of five cases reported by Alexander et al. ${ }^{6}$ No common approach was identified. Treatment was considered by many psychiatrists as unlikely to modify outcome, particularly when the parent showed little insight into the seriousness of her behaviour or lack of commitment to treatment. ${ }^{13}$ There is inevitably a reliance on abusing parents telling and appreciating the truth of their childhood experiences, not only in any psychotherapeutic situation but also in any assessment. Even if the psychiatrists find it hard to treat the underlying personality disturbance, their involvement may help to understand further the reasons why parents suffocate their infant and to guide the courts in their decision making.

In conclusion, the parents of all infants and young children with recurrent cyanotic episodes should undergo careful and incisive history taking to establish whether the episodes have been seen to begin other than in the presence of one carer. If at all possible, it is important to document the pathophysiology of episodes by physiological recordings during a typical episode. When imposed upper airway obstruction is suspected, action must be taken to ensure the safety of the child. This can be done by CVS, but in our experience, confrontation without unequivocal evidence will fail. The involvement of psychiatrists in unravelling the psychopathology could be of great value in further understanding why this form of abuse occurs and assisting the courts in deciding if and when to return an infant to its abusing parent. Finally, long term studies of child rearing practices are needed to help establish the role of poor parenting in the development of this dangerous behaviour. 
We thank all staff who were involved with these cases, particularly the nursing staff who cared for the patients during covert video surveillance and the police officers and detectives at Chelsea Police Station. We are also grateful to Drs Bush, Reddin Ponce Station. We are also grateful to Drs Bush, helped in the clinical management of these patients. Dr Samuels helped in the clinical management of these patients. Dr Samuels is funded by 'Little Ones', Dr Poets by Deutsche Forschungsgemeinschaft, FRG, and Dr Southall by the National Heart and Lung Institu

1 Berger D. Child abuse simulating 'near-miss' sudden infant death syndrome. $\mathcal{F}$ Pediatr 1979;95:554-5.

2 Rosen CL, Frost JD, Glaze DG Child abuse and recurrent infant apnea 7 Pediatr 1986:109:1065-7.

3 Meadow R. Suffocation, recurrent apnea, and sudden infant death. $\mathcal{F}$ Pediatr 1990;117:351-7.

4 Stephenson JBP. Clinics in developmental medicine No 109: fits and faints. Oxford: MacKeith Press, 1990.

5 Makar AF, Squier PJ. Munchausen syndrome by proxy: father as a perpetrator. Pediatrics 1990;85:370-3.

6 Alexander R, Smith W, Stevenson R. Serial Munchausen syndrome by proxy. Pediatrics 1990;86:581-5.

7 Rosen CL, Frost JD. Bricker T, Tarnow JD, Gillette PC, Dunlavy S. Two siblings with recurrent cardiorespiratory arrest: Munchausen syndrome by proxy or child abuse? Pediatrics 1983;71:715-20.

8 Southall DP, Stebbens VA, Rees SV, Lang MH, Warner JO, Shinebourne EA. Apnoeic episodes induced by smothering. two cases identified by covert video surveillance. $B M \mathcal{F}$ 1987;294:1637-41.
9 Williams C, Bevan VT. The secret observation of children in hospital. Lancet 1988; i:780-1.

10 Abraham NG, Stebbens VA, Samuels MP, Southall DP. Investigation of cyanotic/apneic episodes and sleep-related
upper airway obstruction by long-term non-invasive bedupper airway obstruction by long-term non-invasive

11 Poets CF, Samuels MP, Noyes JP, Jones KA, Southall DP Home monitoring of transcutaneous $\mathrm{PO}_{2}$ in the early Home monitoring of transcutaneous $\mathrm{PO}_{2}$ in the early
detection of hypoxaemia in infants and young children. Arch Dis Child 1991;66:676-82.

12 McGuire TL, Feldman KW. Psychological morbidity of children subjected to Munchausen syndrome by proxy. Pediatrics 1989;83:289-92.

13 Nicol AR, Eccles M. Psychotherapy for Munchausen syndrome by proxy. Arch Dis Child 1985;60:344-8.

14 Meadow R. Management of Munchausen syndrome by proxy. Arch Dis Child 1985;60:385-93.

15 Waller DA. Obstacles to the treatment of Munchausen by proxy syndrome. F Am Acad Child Psychiatry 1983;22: po-5.

16 Rogers D, Tripp J, Bentovim A, Robinson A, Berry D, Goulding R. Non-accidental poisoning: an extended syndrome of child abuse. BMF 1976;i:793-6.

17 Meadow $R$. Factitious illness-the hinterland of child abuse. In: Meadow $\mathrm{R}$, ed Recent advances in paediatrics. No 7 . Edinburgh: Churchill Livingstone, 1984:217-32.

18 Korbin JE. Childhood histories of women imprisoned for fatal child maltreatment. Child Abuse Negl 1986;10:331-8.

19 Tuteur W, Glotzer J. Further observations on murdering mothers. F Forensic Sci 1966;11:373-83.

20 Lacey JH, Evans CDH. The impulsivist: a multi-impulsive personality disorder. Br 7 Addict 1986;81:641-9. 